\title{
The effects of hyperventilation on seizure length and cerebral oxygenation during electroconvulsive therapy
}

\author{
(1) Oguz Gundogdu, (1) Onur Avci, (i) Sinan Gursoy, (i) Kenan Kaygusuz, (D) Iclal Ozdemir Kol \\ Department of Anesthesiology and Reanimation, Cumhuriyet University Faculty of Medicine, Sivas, Turkey
}

\begin{abstract}
OBJECTIVE: Previous studies have reported that hyperventilation prolongs seizure length. However, there is no clear consensus in clinical guidelines on how to perform hyperventilation during Electroconvulsive Therapy (ECT). The present study aims to investigate the effects of hyperventilation on seizure length and cerebral oxygenation.

METHODS: Forty patients aged 18-65 and classified as ASA I-II, who would have their first ECT course were included in the study. Ethics committee approval was obtained and all patients' consent was taken. The consecutive patients were randomized into two groups as follows: group $\mathrm{H}$ (20 patients; target etCO $2: 25-30 \mathrm{mmHg}$ ) and group N (20 patients; target etCO $35-40 \mathrm{mmHg}$ ). All patients were ventilated with a facial mask for two minutes and later were ventilated by a laryngeal mask (LMA) for one minute. Vital signs, peripheric oxygen saturation $\left(\mathrm{SpO}_{2}\right)$, and regional oxygen saturation $\left(\mathrm{rSO}_{2}\right)$ were measured before general anesthesia induction, on the $3^{\text {rd }}$ minute of ventilation with an $\mathrm{LMA}\left(\mathrm{LMA}_{3}\right)$, on the $1^{\text {st }}$ minute postictal $\left(\mathrm{PI}_{1}\right)$, on the $5^{\text {th }}\left(\mathrm{PI}_{5}\right)$, and $10^{\text {th }}\left(\mathrm{PI}_{10}\right)$ minutes. The motor seizure duration, Richmond sedation-agitation scale, and the time needed to reach Aldrete Score 9 were also recorded.

RESULTS: There was a significant difference between the groups when they were compared concerning seizure length and recovery time. However, when we compared the $\mathrm{rSO}_{2}$ values that were measured at different times in group $\mathrm{H}$, the difference between the measurements was statistically significant. When $\mathrm{rSO}_{2}$ values in group $\mathrm{H}$ were compared in doubles, there were significant differences between measurements between the basal and $\mathrm{LMA}_{3^{\prime}}$ basal and $\mathrm{PI}_{1^{\prime}}$, and the basal and $\mathrm{PI}_{5}$. When Richmond agitation scores in both groups are compared, there were no significant differences between the groups.

CONCLUSION: This study found that seizure length was longer, and the recovery time was shorter in group $\mathrm{H}$. There was a contribution of hyperventilation on cerebral oxygenation that was measured on the same person at different times, but cerebral oxygenation was not statistically different from patients that were normoventilated. More studies are required to form a consensus regarding how hyperventilation applies to ECT.
\end{abstract}

Keywords: Cerebral oxygenation; electroconvulsive therapy; hyperventilation; seizure length.

Cite this article as: Gundogdu O, Avci O, Gursoy S, Kaygusuz K, Ozdemir Kol I. The effects of hyperventilation on seizure length and cerebral oxygenation during electroconvulsive therapy. North Clin Istanb 2020;7(3):246-254.

E lectroconvulsive shock is applied to one or both cerebral hemispheres to initiate a seizure. Variables of this shock include stimulus pattern, amplitude and duration. The aim of electroconvulsive therapy (ECT) is to create a therapeutic generalized seizure for $25-60$ seconds [1]. Routine use of general anesthesia to induce unconsciousness and to prevent the damage by neuromuscular blockade raised interest in ECT.

Seizure activity is characteristically associated with prolonged sympathetic discharge following an initial parasympathetic discharge. The initial phase is characterized by bradycardia and increased secretion. Sometimes,

Received: January 15, 2019 Accepted: December 12, 2019 Online: April 15, 2020

Correspondence: Dr. Onur AVCI. Cumhuriyet Universitesi Tip Fakultesi, Anesteziyoloji ve Reanimasyon Anabilim Dali, Sivas, Turkey. Tel: +90346258 0125 e-mail: dronuravci@gmail.com

(c) Copyright 2020 by Istanbul Provincial Directorate of Health - Available online at www.northclinist.com 
severe bradycardia and even temporary asystole are seen. Subsequent hypertension and tachycardia usually last a few minutes. Transient autonomic imbalance can make arrhythmias and $\mathrm{T}$-wave changes in electrocardiography. Cerebral blood flow and intracranial pressure, intragastric and intraocular pressures temporarily increase $[2,3]$.

Unconsciousness is only required for a short time (1-5 min) from the delivery of a neuromuscular blocker to the start of a successful therapeutic seizure. The seizure itself usually produces anterograde amnesia, somnolence and often confusion for a short time. As a result, only a short-acting induction agent is required. Since many induction agents (barbiturates, etomidate, benzodiazepines and propofol) have anticonvulsive effects, small doses of them should be used [4]. With all these agents, the seizure threshold increases, and seizure duration is shortened. Due to anesthetic drugs that shorten the seizure duration, many studies have been carried out by anesthesiologists to increase seizure duration without increasing the electrical stimulus, and in some studies, results have shown that hyperventilation prolongs seizure duration [1].

Hyperventilation was first performed according to the number of insufflation. However, the number of insufflation is insufficient to show whether hyperventilation has occurred. Since the number of insufflation can be arbitrarily determined, it has been replaced by end-tidal carbon dioxide $\left(\mathrm{etCO} \mathrm{CO}_{2}\right.$ ), which is a more objective parameter in hyperventilation [5]. There is no consensus on the duration of ventilation. According to a current review about hyperventilation in ECT sessions, ventilation duration was determined as 1 minute, some for two minutes, and in others for three minutes in various studies [6-10].

This study aims to investigate the effects of hyperventilation on seizure length and to research the effects of hyperventilation on the brain metabolic rate, which increases during the electrical current by monitoring cerebral oxygenation.

\section{MATERIALS AND METHODS}

After obtaining the approval of the local ethics committee (2017-12/01), 40 patients were classified as American Society of Anesthesiologists (ASA) I-II, aged between 18-65 years who would have electroconvulsive therapy for their first time under anesthesia, were included in this study. The written consents of the participants were obtained. Patients with uncontrolled cardiovascular, respiratory, metabolic disease, patients that had any intracranial pathology and difficult airway criteria, and patients with a preoperative hemoglobin (hgb) value of less than $10 \mathrm{~g} / \mathrm{dl}$ or above $17 \mathrm{~g} / \mathrm{dl}$ were excluded from this study. In addition, patients that were taking lithium, sodium valproate and benzodiazepines were included in this study but these patients discontinued lithium for two weeks, sodium valproate for five days and benzodiazepines for two days before the ECT session.

The age, weight, gender, hemoglobin levels and psychiatric diagnoses of the patients were evaluated preoperatively and were recorded. Patients who underwent electroconvulsive therapy for the first time under anesthesia without premedication due to their effect on the convulsion threshold, were taken to the operating table. Before anesthesia induction, systolic blood pressure (SBP), diastolic blood pressure (DBP), mean arterial pressure (MAP), heart rate (HR), peripheral oxygen saturation $\left(\mathrm{SpO}_{2}\right)$, and regional oxygen saturation $\left(\mathrm{rSO}_{2}\right)$ values were recorded. These values were taken as basal values. Following induction of general anesthesia, etCO $\mathrm{CO}_{2}$ values were recorded at the third minute of the ventilation and at the first minute of convulsion of patients with their airway controlled by a laryngeal mask (LMA). Following general anesthesia induction, hyperventilation with an LMA (target etCO $25-30 \mathrm{mmHg}$ ) to one group of 20 patients (group $\mathrm{H}$ ), normoventilation (target et $\mathrm{CO}_{2}$ $35-40 \mathrm{mmHg}$ ) with a laryngeal mask to the other group of 20 patients (group N) were applied with $\mathrm{O}_{2} 100 \% 6$ $\mathrm{lt} / \mathrm{min}$ for three minutes. The consecutive patients were randomized to group $\mathrm{H}$ or group $\mathrm{N}$. The preoxygenation was completed after general anesthesia induction with a facial mask (FM) for two minutes until reaching the maximum muscle relaxation. Subsequently, the preoxygenation laryngeal mask was applied to the patients. The ventilation maneuvers were stopped when the electrical stimulus started. Ventilation maneuvers were applied according to targeted etCO $\mathrm{O}_{2}$ intervals.

All procedures performed under general anesthesia may cause impaired brain perfusion, especially in elderly patients [11]. However, in routine practice, the brain is rarely monitored. Many studies have shown that monitoring cerebral oxygen saturation in the intraoperative period is a convenient and useful method. Near-infrared spectroscopy (NIRS) monitoring is a noninvasive anal$y$ sis method that demonstrates regional cerebral oxygenation that presents venous values with brain oxyhemoglobin and deoxyhemoglobin tissue concentration [12]. Our device (Somanetics INVOS oximeter) used in this study to measure cerebral oxygenation works with 
TABLE 1. Modified Aldrete and Richmond Sedation-Agitation Scales

Modified Aldrete Scale

\section{Consciousness}

Totally awake and oriented (name, place, time) (2).

Response to voice (1).

No response (0).

Activity

Moves all the extremities voluntarily and in accordance with the orders (2).

Moves only two extremities (1).

No movement (0).

Breathing

Can breathe deeply and cough (2).

Dyspnea, limited breathing or tachypnea (1).

Apneic or with mechanical ventilation support (0).

Circulation

Blood pressure is $\pm 20 \%$ of the pre-anesthetic value (2).

Blood pressure is $\pm 20-49 \%$ of the pre-anesthetic value (1).

Blood pressure is $\pm 50 \%$ of the pre-anesthetic value (0).

Oxygen saturation

Room-air $\mathrm{SpO}_{2}>92 \%$ (2).

Need $\mathrm{O}_{2}$ support for $\mathrm{SpO}_{2}>90 \%$ (1).

Although $\mathrm{O}_{2}$ support, $\mathrm{SpO}_{2}<90 \%$ (0).
Richmond Sedation-Agitation Scale

+4 Combative/Violent/Staff is in danger

+3 Very agitated/Pulls or removes tubes or catheters/Aggressive

+2 Agitated/Non-purposeful movements/Fights ventilator

+1 Restless/Anxious but movements are not aggressively vigorous 0 Alert and calm

-1 Drowsy/Not fully alert but has sustained awakening/ eye-opening to voice $>10 \mathrm{sn}$.

-2 Light sedation/Briefly awakening to voice with eye contact (<10 sn).

-3 Moderate sedation/Movement or eye-opening to voice but no eye contact

-4 Deep sedation/No response to voice but movement response

to physical stimulation

-5 Unarousable/No response to voice or physical stimulation
NIRS technology. The cerebral oximeter was applied unilaterally to the patients' left temporal region.

The ECT electrodes were applied to frontotemporal regions of the patients bilaterally. The protocol for seizure threshold titration starts with the administration of an initial stimulus of 48 millicoulombs $(\mathrm{mC})$ for women receiving bilateral ECT, and $60 \mathrm{mC}$ for men receiving bilateral ECT. The maximum stimulus charge was $504 \mathrm{mC}$ (THYMATRON ${ }^{\mathrm{TM}}$ DGx Somatics, INC).

Before the electrical current and postictal $1^{\text {st }}, 5^{\text {th }} 10^{\text {th }}$ minutes, convulsion times were recorded with SBP, DBP, MAP, $\mathrm{HR}, \mathrm{SpO}_{2}$ and $\mathrm{rSO}_{2}$ values. The efficacy of the given electrical current was determined by observing convulsive movements in the patient's extremities. When the electrical stimulus was ended, and the convulsive movements in the extremities were started, a chronometer was started, and it was stopped when the movements were ended. Then, this duration was recorded as the motor seizure duration.

After the patients were awakened, the time required for the modified Aldrete recovery score to be 9 and ag- itation scores using the Richmond agitation-sedation scale (RASS) were determined and recorded (Table 1). The RASS score was determined at the $10^{\text {th }}$ minute after ECT. In the induction of general anesthesia, propofol (Fresenius Kabi 2\%) was used at a dose of $2.5 \mathrm{mg} / \mathrm{kg}$ and rocuronium as a muscle relaxant at a dose of $0.6 \mathrm{mg} / \mathrm{kg}$. Sugammadex (Schering-plough $100 \mathrm{mg} / \mathrm{ml}$ ) was administered to patients at a dose of $4 \mathrm{mg} / \mathrm{kg}$ after convulsion at the adequate time and quality.

\section{Statistical Methods}

The data obtained from our study were loaded into the SPSS (ver: 22.0) program. Parametric test assumptions were performed (Kolmogorov-Smirnov) in the evaluation of the data, and variance analysis was used in repetitive measurements in comparing the measurements obtained at different times or situations in the same individuals. The Bonferroni test was used to find the measurement, or measurement groups, which that differ when the decision was made as significant as a result of the analysis. In the comparison of the measurements of 


\begin{tabular}{|c|c|c|c|}
\hline & $\begin{array}{c}\text { Group H } \\
\text { Mean } \pm \text { SD }\end{array}$ & $\begin{array}{c}\text { Group N } \\
\text { Mean } \pm \text { SD }\end{array}$ & $\mathrm{p}$ \\
\hline \multicolumn{4}{|l|}{$\begin{array}{l}\text { Mean arterial } \\
\text { pressure }(\mathrm{mmHg})\end{array}$} \\
\hline Basal & $92.85 \pm 11.62$ & $90.65 \pm 8.42$ & $0.49 *$ \\
\hline LMA $3^{\text {rd }}$ minute & $92.35 \pm 11.62$ & $89.90 \pm 9.51$ & $0.47 *$ \\
\hline Postictal $1^{\text {st }}$ minute & $96.25 \pm 15.11$ & $95.40 \pm 9.70$ & $0.83 *$ \\
\hline Postictal $5^{\text {th }}$ minute & $93.50 \pm 10.95$ & $92.70 \pm 7.22$ & $0.78^{*}$ \\
\hline $\begin{array}{l}\text { Postictal } 10^{\text {th }} \text { minute } \\
\text { Heart rate } \\
\text { (beat/minute) }\end{array}$ & $91.45 \pm 10.34$ & $91.05 \pm 7.22$ & $0.88^{*}$ \\
\hline Basal & $80.30 \pm 9.81$ & $76.15 \pm 11.33$ & $0.22 *$ \\
\hline LMA $3^{\text {rd }}$ minute & $84.45 \pm 10.10$ & $79.30 \pm 10.07$ & $0.11^{*}$ \\
\hline Postictal $1^{\text {st }}$ minute & $88.40 \pm 13.92$ & $88.75 \pm 12.15$ & $0.93 *$ \\
\hline Postictal $5^{\text {th }}$ minute & $87.60 \pm 12.15$ & $84.80 \pm 10.77$ & $0.44 *$ \\
\hline Postictal $10^{\text {th }}$ minute & $86.20 \pm 12.94$ & $82.15 \pm 10.00$ & $0.27 *$ \\
\hline \multicolumn{4}{|l|}{$\begin{array}{l}\text { Peripheral oxygen } \\
\text { saturation }\left(\mathrm{SpO}_{2}\right)(\%)\end{array}$} \\
\hline Basal & $97.50 \pm 2.21$ & $97.60 \pm 1.72$ & $0.87 *$ \\
\hline LMA $3^{\text {rd }}$ minute & $99.70 \pm 0.80$ & $99.65 \pm 0.58$ & $0.82 *$ \\
\hline Postictal $1^{\text {st }}$ minute & $99.45 \pm 0.99$ & $99.55 \pm 0.75$ & $0.72 *$ \\
\hline Postictal $5^{\text {th }}$ minute & $98.30 \pm 2.20$ & $98.00 \pm 2.24$ & $0.67 *$ \\
\hline Postictal $10^{\text {th }}$ minute & $98.15 \pm 1.98$ & $98.10 \pm 1.68$ & $0.93 *$ \\
\hline
\end{tabular}

SD: Standard deviation; LMA: Laryngeal mask airway; *: p>0.05 insignificant; Mann-Whitney $\mathrm{U}$ test was used for the comparison.

the individuals in both groups at different times, the significance test of the difference between two means and the significance test of the difference between two peers were used. The Chi-square test and correlation analysis with the Pearson test were used to evaluate the data obtained by counting. The data were included in tables with their arithmetic mean, standard deviation, number, and the percentage of individuals. The margin of error was taken as 0.05 . When the parametric test assumptions were not fulfilled, the Man-Whitney $U$ test was applied, and the margin of error was taken as 0.05 .

\section{RESULTS}

The difference between the groups concerning gender was insignificant in the individuals included in this study $\left(x^{2}=1.61 ; p=0.204 ; p>0.05\right)$. No significant difference was found between preoperative hemoglobin levels with the comparison with the groups $(\mathrm{p}>0.05)$.

\begin{tabular}{|c|c|c|c|c|}
\hline $\begin{array}{l}\text { Time of } \\
\text { measurement }\end{array}$ & $\begin{array}{c}\text { Ventilation } \\
\text { method }\end{array}$ & $\begin{array}{c}\text { Mean } \pm S D \\
(n=20)\end{array}$ & Result & $\mathrm{p}$ \\
\hline LMA $3^{\text {rd }}$ & Hyperventilation & $26.75 \pm 1.29$ & $t=14.01$ & $0.001 *$ \\
\hline minute etCO & Normoventilation & $36.75 \pm 2.91$ & & \\
\hline PI $1^{\text {st }}$ & Hyperventilation & $27.45 \pm 1.43$ & $t=14.94$ & $0.001 *$ \\
\hline minute et $\mathrm{CO}_{2}$ & Normoventilation & $37.50 \pm 2.64$ & & \\
\hline
\end{tabular}

SD: Standard deviation; LMA: Laryngeal mask airway; etCO ${ }_{2}$ : End-tidal carbon dioxide; PI: Postictal; ${ }^{*} \mathrm{p}<0.05$ significant; $\mathrm{t}=\mathrm{t}$-test results between groups; $\mathrm{n}=$ Number of patients.

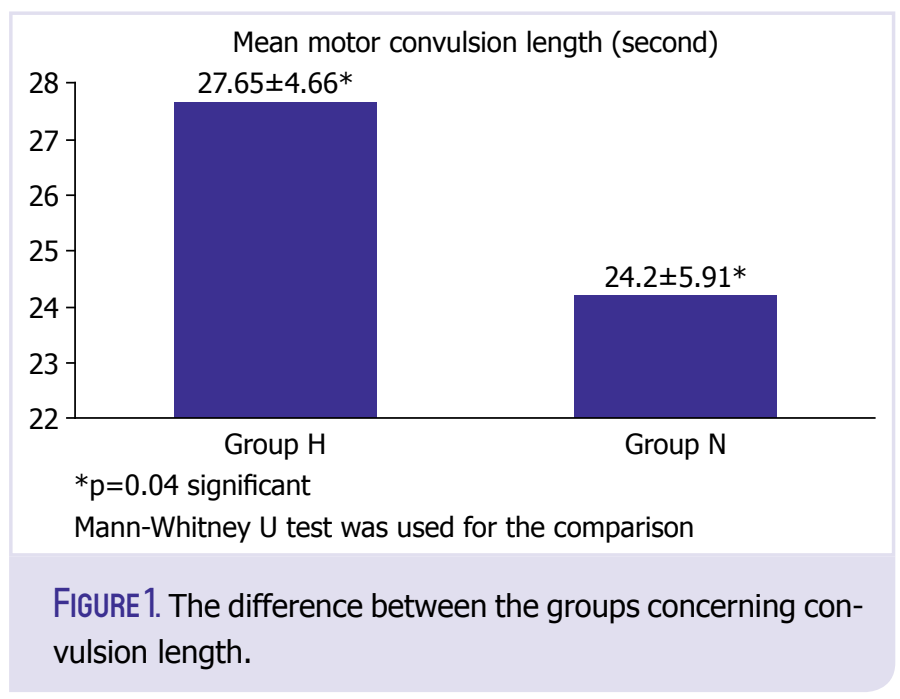

The mean age of the patients who underwent hyperventilation was $38.5 \pm 10.70$, and the mean age of the patients who underwent normoventilation was $37.5 \pm 8.90$. The difference between the groups concerning age was insignificant $(t=0.32: p=0.750: p>0.05)$.

The difference between the groups was found to be insignificant when SBP, DBP, MAP, $\mathrm{HR}, \mathrm{SpO}_{2}$ and $\mathrm{rSO}_{2}$ values were measured at different times in both groups and were compared $(p>0.05)$ (Table 2). When the LMA $3^{\text {rd }}$ min and postictal $1^{\text {st }}$ min etCO values of the two groups were compared, the difference was significant $(\mathrm{p}<0.01)$ (Table 3). When patients in both groups were compared for the duration of convulsion and recovery time, the difference between the groups was significant $(p<0.05)$ (Fig. 1, 2 ). When the Richmond Agitation scores of the two groups were compared, the difference was insignificant $(p>0.05)$.

Comparing the $\mathrm{rSO}_{2}$ values measured at different times the group $\mathrm{H}$, the difference between the measurements was significant $(\mathrm{p}<0.05)$. When $\mathrm{rSO}_{2}$ values in 


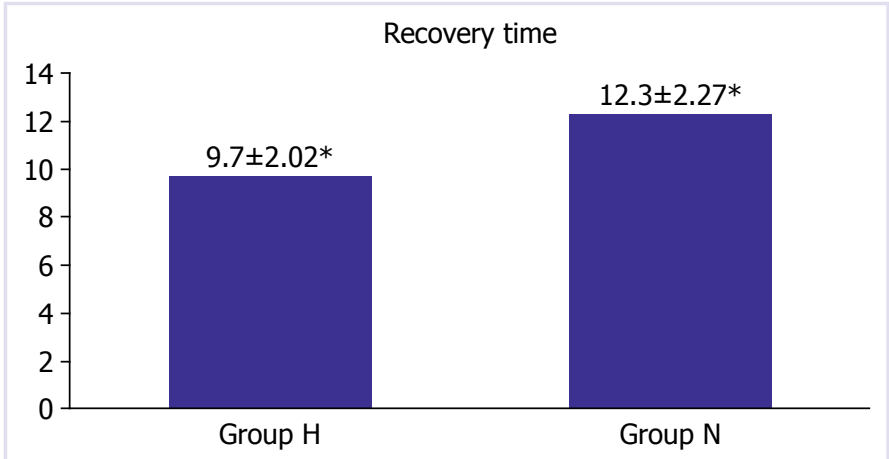

Recovery time: The time needed to reach Modified Aldrete Score to be 9 for each patient

${ }^{*} \mathrm{p}=0.001$ significant

Mann-Whitney $U$ test was used for the comparison

FIGURE 2 . The difference between the groups concerning recovery time.
TABLE 5. The correlations between cerebral oxygenation $\left(\mathrm{rSO}_{2}\right)$ and preoperative hemoglobin (hgb) values and in group $\mathrm{N}$ $\mathrm{p}$

correlation

coefficient

\begin{tabular}{lll}
\hline Basal $\mathrm{rSO}_{2}$-preop hgb & 0.55 & $0.01^{*}$ \\
LMA $3^{\text {rd }}$ minute $\mathrm{rSO}_{2}$-preop hgb & 0.65 & $0.002^{*}$ \\
PI $1^{\text {st }}$ minute $\mathrm{rSO}_{2}$-preop hgb & 0.60 & $0.005^{*}$ \\
PI $5^{\text {th }}$ minute $\mathrm{rSO}_{2}$-preop hgb & 0.55 & $0.01^{*}$ \\
PI $10^{\text {th }}$ minute $\mathrm{rSO}_{2}$-preop hgb & 0.52 & $0.01^{*}$ \\
\hline
\end{tabular}

rSO2: Regional cerebral oxygenation saturation; preop hgb: Preoperative hemoglobin value; LMA: Laryngeal mask airway; PI: Postictal; *p<0.05 significant.

TABLE 4. Distribution of the cerebral oxygenation $\left(\mathrm{rSO}_{2}\right)$ values within the groups

\begin{tabular}{|c|c|c|c|c|}
\hline Technic & Time of measurement & Mean \pm SD & Result & $\mathrm{p}$ \\
\hline \multirow[t]{5}{*}{ Hyperventilation } & Basal $\mathrm{rSO}_{2}$ & $74.25 \pm 7.85$ & & \\
\hline & $\mathrm{LMA}^{\text {rd }}$ minute $\mathrm{rSO}_{2}$ & $78.60 \pm 9.05$ & & \\
\hline & PI $1^{\text {st }}$ minute $\mathrm{rSO}_{2}$ & $80.90 \pm 9.26$ & $F=18.16$ & $0.001^{*}$ \\
\hline & PI $5^{\text {th }}$ minute $\mathrm{rSO}_{2}$ & $79.75 \pm 9.04$ & & \\
\hline & PI $10^{\text {th }}$ minute $\mathrm{rSO}_{2}$ & $78.30 \pm 9.17$ & & \\
\hline \multirow[t]{5}{*}{ Normoventilation } & Basal rSO & $74.00 \pm 7.26$ & & \\
\hline & $\mathrm{LMA}^{\text {rd }}$ minute $\mathrm{rSO}_{2}$ & $76.05 \pm 9.16$ & & \\
\hline & PI $1^{\text {st }}$ minute $\mathrm{rSO}_{2}$ & $76.45 \pm 8.61$ & $F=3.89$ & 0.06 \\
\hline & PI $5^{\text {th }}$ minute $\mathrm{rSO}_{2}$ & $75.65 \pm 9.37$ & & \\
\hline & PI $10^{\text {th }}$ minute $\mathrm{rSO}_{2}$ & $74.95 \pm 9.47$ & & \\
\hline
\end{tabular}

$\mathrm{SD}$ : Standard deviation; $\mathrm{rSO}_{2}$ : Regional cerebral oxygenation saturation; LMA: Laryngeal mask airway; PI: Postictal; $* * * * p<0.05$ significant in Hyperventilation group; $\mathrm{F}=$ Friedman analysis of variance test results between groups.

group $\mathrm{H}$ were compared in doubles, there was a significant difference in measurements between the basal and $\mathrm{LMA}_{3}$, basal and $\mathrm{PI}_{1}$, basal and $\mathrm{PI}_{5}$ and the difference between the other measurements was found to be insignificant. Comparison of the $\mathrm{rSO}_{2}$ values measured at different times in group $\mathrm{N}$ showed the difference between the measurements to be insignificant $(p>0.05)$ (Table 4).

In group $\mathrm{H}$, there was no significant correlation between hemoglobin values and $\mathrm{rSO}_{2}$ measurements that were measured at different times. The same directional positive correlations were found between hemoglobin$\mathrm{rSO}_{2}$ in group $\mathrm{H}$, but these correlations were statistically insignificant.
In group $\mathrm{N}$, the same directional correlation coefficients were found between the hgb-basal $\mathrm{rSO}_{2}$ $(\mathrm{r}=0.551)$, the hgb-LMA $3^{\text {rd }} \mathrm{rSO}_{2}(\mathrm{r}=0.654)$, hgb-PI $1^{\text {st }}$ $\mathrm{rSO}_{2}(\mathrm{r}=0.657), \mathrm{hgb}-\mathrm{PI} 5^{\text {th }} \mathrm{rSO}_{2}(\mathrm{r}=0.557)$ and $\mathrm{hgb}-\mathrm{PI}$ $10^{\text {th }} \mathrm{rSO}_{2}(\mathrm{r}=0.525)$. These correlation coefficients were statistically significant. Accordingly, when the hgb value increased, $\mathrm{rSO}_{2}$ values of the basal, LMA $3^{\text {rd }}$, PI $1^{\text {st }}, \mathrm{P}_{\mathrm{I}}$ $5^{\text {th }}$, and $\mathrm{P}_{\mathrm{I}} 10^{\text {th }}$ minutes increased (Table 5).

Furthermore, a negative correlation was found in both groups between the values of MAP measured at different times and $\mathrm{rSO}_{2}$ values also measured at different times. However, these correlation coefficients were statistically insignificant. 
In only one patient, hemorrhagic secretion was observed due to the LMA application after the ECT course. No further side effects were observed due to LMA and ventilation maneuvers.

\section{DISCUSSION}

Ventilation has a role in increasing the effectiveness of ECT by prolonging seizure duration [13]. The electrical dose is usually increased to pass the seizure threshold, which may lead to a transient weakening of cognitive functions. Therefore, an optimal dose adjustment is required in ECT.

Many pro-convulsant strategies have been attempted to avoid increasing the electrical dose. These include methylxanthine drugs, such as caffeine and theophylline, opioids (remifentanil), flumazenil, etomidate, anesthetic drugs, such as ketamine, sleep deprivation and hyperventilation alone [1,14-18]. All of these applications reduce the seizure threshold and the required dose of electrical dose for convulsions [19].

Today, clinical guidelines do not have a clear view of how ventilation should be in ECT. Each patient is routinely pre-oxygenated and is intended to achieve a reliable duration of apnea during the seizure by filling intrapulmonary oxygen reserves. In some sources, hyperventilation with pre-oxygenation is recommended, but the optimal hyperventilation maneuvers are not indicated [8]. The role of hyperventilation for prolonging the seizure duration has been investigated for many years, and these studies were collected in a current review of Gómez-Arnau et al. [6]. We also took this review as a guide for determining our methods in this study.

In our study, we placed a laryngeal mask after induction of general anesthesia to the oropharynx of the individuals and provided 3-minute ventilation before the electrical current was delivered. During this procedure, we performed end-tidal $\mathrm{CO}_{2}$ monitoring with a capnograph in the breathing circuit that was connected to the LMA. etCO ${ }_{2}$ reflects the maximum $\mathrm{CO}_{2}$ concentration at the end of each exhalation and is close to the arterial $\mathrm{CO}_{2}$ value in people without a pulmonary disease [7]. Although et $\mathrm{CO}_{2}$ monitoring in ECT is a useful monitor for controlling hemodynamic parameters, there is no effective monitoring due to mask leaks in patients who are ventilated with a facial mask (FM). Thus, we used an LMA instead of a facial mask for effective etCO $\mathrm{C}_{2}$ monitoring. Because of minimal leaks, better airway control, and better ventilation features, LMA could be a firstline option to manage airway and ventilation in ECT in the future, although nowadays, facial mask ventilation is the most frequently used method. In addition, the most optimal way to determine the level of $\mathrm{CO}_{2}$ would be to intubate the patient and follow etCO $\mathrm{C}_{2}$ and to look for $\mathrm{PaCO}_{2}$ in the patient's arterial blood gas. However, we did not implement this technique because it would be a much more invasive attempt. Due to its invasiveness, intubation is not a common practice in ECT [7].

The facial mask is the most widely used ventilation device for ECT ventilation. However, the facial mask is criticized by many authors since it cannot provide airway security effectively. Instead, a minimally invasive laryngeal mask is recommended $[10,13]$. In the study performed in patients with difficult ventilation, the LMA was compared with the FM and patients with an LMA having lower $\mathrm{PaCO}_{2}$ and longer seizures [10]. In other studies supporting this study, LMA-related positive results were obtained and many authors noted that a more tolerable side effect profile of ECT has been established by reducing the electrical dose that is needed for stimulus in ECT patients ventilated with LMA [13]. However, routine use of the LMA in ECT is not currently recommended in clinical guidelines [8].

We assumed that three minutes of hyperventilation is enough to reach the target values of etCO $2_{2}$. The long duration of ventilation may affect the depth of anesthesia and may cause excessive hypocapnia because of a long period between general anesthesia induction and electrical stimulation in ECT. Bergsholm et al. [7] made severe hypocapnia, and the target etCO $\mathrm{C}_{2}$ value was $15 \mathrm{mmHg}$. Many other authors have determined the target etCO as $30 \mathrm{mmHg}[5,8,9,13]$.

Pande et al. [20] evaluated hyperventilation in three stages; etCO $\mathrm{CO}_{2}$ values were determined as 20,25 and 30 $\mathrm{mmHg}$ in three different groups, and he did not find a significant difference in seizure durations.

In another study, there was no difference between the $18 \mathrm{mmHg}$ targeted etCO $\mathrm{m}_{2}$ and $25 \mathrm{mmHg}$ targeted etCO $\mathrm{C}_{2}$ groups concerning seizure duration [21]. According to the results of these studies, hyperventilation due to the target etCO $\mathrm{Cf}_{2}$ less than $30 \mathrm{mmHg}$ may not show any additional benefits in ECT. On the other hand, there is still no consensus on what the target etCO should be.

In addition to the seizure duration, quality parameters, such as ictal amplitude and postictal suppression index, were also used to assess seizure adequacy. In fact, 
these parameters are used to evaluate the effects of ECT on the patient's clinical situation [22]. Although there is evidence of the relationship between hyperventilation and seizure quality, some authors have used these seizure quality parameters [23]. In our study, we did not assess seizure quality with these parameters. Only seizure duration was determined by observing the extremity movements of the patients.

Haeck et al. [13] found a significantly higher ictal intensity in the hyperventilated patient group with an LMA. Di Pauli et al. [21] reported a higher level of postictal suppression index and amplitude in the group of patients hyperventilated with LMA by keeping the target et $\mathrm{CO}_{2}$ around $28 \mathrm{mmHg}$. When cerebral blood flow was altered by excessive maneuvers, the efficacy of NIRS to detect sudden changes in cerebral oxygenation was determined by Levy et al. [24].

Aydin et al. [25] randomly divided their 40 patients into two groups in their study referred to as "brain oxygenation during electroconvulsive therapy". Following general anesthesia induction, one group (group $\mathrm{O}$ ) was given oxygen at $61 / \mathrm{min}$ with the nasal cannula and not applied to the other group (group K). There were no statistically significant differences between the groups after 10 minutes of measuring cerebral oxygenation with NIRS. In addition, five patients had desaturation during seizures, and four of them were in group $\mathrm{K}$, with no oxygen. Three of these five patients were accompanied by cerebral desaturation. In addition, postictal et $\mathrm{CO}_{2}$ values were significantly higher in group $\mathrm{K}$. This is probably due to the lack of adequate filling of the pulmonary reservoirs with preoxygenation and alveolar hypoventilation after the seizure.

Saito et al. [26] investigated the change in cerebral oxygenation using NIRS in electroconvulsive therapy and found a correlation between $\mathrm{rSO}_{2}$ values and mean arterial pressure that decreased at the time of the seizure and then increased and came back to basal levels. However, in this 43 patient study of Saito et al's, patients were premedicated with atropine sulfate $(0.01 \mathrm{mg} / \mathrm{kg} \mathrm{IM})$. It should be noted that this may affect the cardiac functions of the patient. In our study, no statistically significant correlation was found between mean arterial pressure and cerebral oxygenation in patients without premedication. This is possibly because of the patient's unstable arterial blood pressure values due to cardiac arrhythmia caused by electrical currents applied to the patient. et $\mathrm{CO}_{2}$ values were kept between 30 and $35 \mathrm{mmHg}$ in all patients in this study, where we cannot reach satisfactory information about how ventilation is done. Therefore, it is difficult to say whether hyperventilation in ECT contributes to $\mathrm{rSO}_{2}$ due to Saito et al's study.

We found that the effects of ECT on cerebral oxygenation were examined in our literature search, but the studies about the relationship between hyperventilation/ hypocapnia and cerebral oxygenation were insufficient. In this sense, our study is important.

Some authors have defined cerebral tissue desaturation as an absolute $\mathrm{rSO}_{2}$ below $50 \%$, or more than a $20 \%$ reduction from the baseline. Other researchers have used a decline of over $20 \%$ of the baseline value as the cutoff value for cerebral ischemia-hypoxia. Monitor based cerebral NIRS on continuous-wave technology is a trend monitor. Consequently, clinical decision-making should be based on the change from baseline together with the clinical situation instead of the absolute value observed [27]. In our study, we consider a decline of over $20 \%$ of the baseline value as the cut-off value and none of our patients' $\mathrm{rSO}_{2}$ values decreased below this level.

The condition limiting our study is that we cannot detect basal et $\mathrm{CO}_{2}$ in patients because we use a laryngeal mask after general anesthesia induction. Detecting how much the etCO $\mathrm{CO}_{2}$ values decrease from their basal values could be an effective parameter in determining the depth of hyperventilation. In addition, data analysis could not be performed according to the diagnosis because the patients were not distributed equally according to their diagnoses. Seizure duration alone should not serve as a marker of the adequacy of treatment. Some research strongly suggests that there are complex relations between stimulus dosing and seizure duration, as when the electrical stimulus is increased further above the seizure threshold, the seizure duration may actually decrease particularly early in the treatment course [28]. This makes the seizure duration a confusing and inadequate outcome measure, despite this, due to its ease, it is still one of the most used. The study did not report the effects on seizure quality, which is a factor to guide clinical decisions during the ECT, together with seizure length and patient's clinical response. Not monitoring the electrical seizure with EEG was another limiting condition of this study.

In conclusion, our study discussed a controversial issue such as hyperventilation in ECT, which could not reach a definite consensus in the world. Seizure duration is determined as longer in the group of patients, which were hyperventilated. According to the analysis of the 
obtained $\mathrm{rSO}_{2}$ data, hyperventilation was found to have a significant contribution to cerebral oxygenation measured at different times in the same individual. However, there was no statistically significant difference from group N.

It was also found that the duration of recovery in group $\mathrm{H}$ was shorter than the group $\mathrm{N}$. We contend that because of the $\mathrm{rSO}_{2}$ values is higher in group $\mathrm{H}$ than group $\mathrm{N}$, the recovery time was found to be shorter. In hyperventilated patients, cerebral oxygenation is more protected and this situation can be a reason to have a shorter recovery time. The recovery time in hyperventilation has also been found to be shorter in a study of Mayur et al. [29] and in another study of De Arriba-Arnau et al. [30].

To make a definitive judgment on how to perform hyperventilation in ECT and to investigate hyperventilation effect controlling for other potential confounder variables, future controlled studies are needed. The entire ECT course should be considered to understand the longitudinal effects of hyperventilation during the sessions and its effects on clinical outcomes or seizure threshold.

Acknowledgements: We thank all members of the Department Anesthesiology, Faculty of Medicine.

Ethics Committee Approval: Cumhuriyet University Clinical Research Ethics Committee granted approval for this study (date: 12.12.2017, number: 2017-12/01).

Conflict of Interest: No conflict of interest was declared by the authors.

Financial Disclosure: The authors declared that this study has received no financial support.

Authorship Contributions: Concept - OG, OA, SG; Design - KK, IOK; Supervision - OG, OA, SG; Fundings - SG, KK, IOK; Materials - OG, OA, SG; Data collection and/or processing - OG, OA, SG; Analysis and/or interpretation - SG, KK, IOK; Literature review - SG, KK, IOK; Writing - OG, OA, SG; Critical review - OG, OA, SG.

\section{REFERENCES}

1. Weiner RD. American Psychiatric Association Committee on Electroconvulsive Therapy. The practice of electroconvulsive therapy: recommendations for treatment, training, and privileging. $2^{\text {nd }} \mathrm{ed}$. Washington DC: American Psychiatric Association; 2002. p. 1040-1.

2. Wells DG, Davies GG, Rosewarne F. Attenuation of electroconvulsive therapy induced hypertension with sublingual nifedipine. Anaesth Intensive Care 1989;17:31-3. [CrossRef]

3. McCall WV. Asystole in electroconvulsive therapy: Report of four cases. J Clin Psychiatry 1996;57:199-203.

4. Gürsoy Y, Sağıroğlu E. Elektrokonvülsif tedavi ve anestezi. In: Çelikkol A, editor. Elektrokonvülsif Tedavi. İzmir: Ege Psikiyatri Sürekli Yayınları, Ege Üniversitesi Basımevi: 1998. p. 333.
5. Chater SN, Simpson KH. Effect of passive hyperventilation on seizure duration in patients undergoing electroconvulsive therapy. Br J Anaesth 1988;60:70-3. [CrossRef]

6. Gómez-Arnau J, de Arriba-Arnau A, Correas-Lauffer J, Urretavizcaya M. Hyperventilation and electroconvulsive therapy: A literature review. Gen Hosp Psychiatry 2018;50:54-62. [CrossRef]

7. Bergsholm P, Bleie H, Gran L, d'Elia G. Cardiovascular response and seizure duration as determined by electroencephalography during unilateral electroconvulsive therapy. Acta Psychiatr Scand 1993;88:25-8.

8. de Arriba-Arnau A, Dalmau A, Salvat-Pujol N, Soria V, Bocos J, Menchón JM, et al. Hypocapnia and hyperoxia induction using a hyperventilation protocol in electroconvulsive therapy. Rev Psiquiatr Salud Ment 2017;10:21-7. [CrossRef]

9. Nishikawa K, Yamakage M. Reconsideration of Augmentation Strategies in Electroconvulsive Therapy: Effects of the Concurrent Use of a Reduced Dose of Propofol with Divided Supplemental Remifentanil and Moderate Hyperventilation on Electroconvulsive Therapy-Induced Seizure Production and Adverse Events. Open J Anaesthesiol 2015;5:219-26. [CrossRef]

10. Nishihara F, Ohkawa M, Hiraoka H, Yuki N, Saito S. Benefits of the laryngeal mask for airway management during electroconvulsive therapy. J ECT 2003;19:211-6. [CrossRef]

11. Moller JT, Cluitmans P, Rasmussen LS, Houx P, Rasmussen H, Canet $\mathrm{J}$, et al. Long-term postoperative cognitive dysfunction in the elderly ISPOCD1 study. ISPOCD investigators. International Study of PostOperative Cognitive Dysfunction. Lancet 1998;351:857-61. [CrossRef]

12. Redford D, Paidy S, Kashif F. Absolute and trend accuracy of a new regional oximeter in healthy volunteers during controlled hypoxia. Anesth Analg 2014;119:1315-9. [CrossRef]

13. Haeck M, Gillmann B, Janouschek H, Grözinger M. Electroconvulsive therapy can benefit from controlled hyperventilation using a laryngeal mask. Eur Arch Psychiatry Clin Neurosci 2011;261 Suppl 2:S172-6.

14. Stern L, Dannon PN, Hirschmann S, Schriber S, Amytal D, Dolberg OT, et al. Aminophylline increases seizure length during electroconvulsive therapy. J ECT 1999;15:252-7. [CrossRef]

15. Porter R, Booth D, Gray H, Frampton C. Effects of the addition of remifentanil to propofol anesthesia on seizure length and postictal suppression index in electroconvulsive therapy. J ECT 2008;24:203-7.

16. Yi J, Torres J, Azner Y, Vaidya P, Schiavi A, Reti IM. Flumazenil pretreatment in benzodiazepine-free patients: a novel method for managing declining ECT seizure quality. J ECT 2012;28:185-9. [CrossRef]

17. Trevithick L, McAllister-Williams RH, Blamire A, Branton T, Clark $\mathrm{R}$, et al. Study protocol for the randomised controlled trial: Ketamine augmentation of ECT to improve outcomes in depression (KetamineECT study). BMC Psychiatry 2015;15:257. [CrossRef]

18. Gilabert E, Rojo E, Vallejo J. Augmentation of electroconvulsive therapy seizures with sleep deprivation. J ECT 2004;20:242-7. [CrossRef]

19. Loo C, Simpson B, MacPherson R. Augmentation strategies in electroconvulsive therapy. J ECT 2010;26:202-7. [CrossRef]

20. Pande AC, Shea J, Shettar S, Grunhaus LJ, Haskett RF. Effect of hyperventilation on seizure length during electroconvulsive therapy. Biol Psychiatry 1990;27:799-801. [CrossRef]

21. Di Pauli J, Pfanner G, Grözinger M, Penz D, Conca A. Controlled Hyperventilation by Laryngeal Mask during Electroconvulsive Therapy and the Impact on Seizure Quality. Biol Psychiatry 2009;65:222S-3.

22. Folkerts $H$. The ictal electroencephalogram as a marker for the efficacy of electroconvulsive therapy. Eur Arch Psychiatry Clin Neurosci 1996;246:155-64. [CrossRef]

23. Aksay SS, Bumb JM, Janke C, Hoyer C, Kranaster L, Sartorius A. 
New evidence for seizure quality improvement by hyperoxia and mild hypocapnia. J ECT 2014;30:287-91. [CrossRef]

24. Levy WJ, Levin S, Chance B. Near-infrared measurement of cerebral oxygenation. Anesthesiology 1995;83:738-46. [CrossRef]

25. Aydın BG, Küçükosman G, Atasoy N. Cerebral oxygenation during electroconvulsive therapy. Anadolu Psikiyatri Dergisi 2018;19:472-7.

26. Saito S, Miyoshi S, Yoshikawa D, Shimada H, Morita T, Kitani Y. Regional cerebral oxygen saturation during electroconvulsive therapy: monitoring by near-infrared spectrophotometry. Anesth Analg 1996;83:726-30. [CrossRef]

27. Fenton KN, Freeman K, Glogowski K, Fogg S, Duncan KF. The sig- nificance of baseline cerebral oxygen saturation in children undergoing congenital heart surgery. Am J Surg 2005;190:260-3. [CrossRef]

28. Sackeim HA. Optimizing Unilateral Electroconvulsive Therapy. Convuls Ther 1991;7:201-12.

29. Mayur P, Bray A, Fernandes J, Bythe K, Gilbett D. Impact of hyperventilation on stimulus efficiency during the early phase of an electroconvulsive therapy course: a randomized double-blind study. J ECT 2010;26:91-4. [CrossRef]

30. de Arriba-Arnau A, Dalmau A, Soria V, Salvat-Pujol N, Ribes C, Sánchez-Allueva A, et al. Protocolized hyperventilation enhances electroconvulsive therapy. J Affect Disord 2017;217:225-32. [CrossRef] 